\title{
Effects of the Coastal Park Environment Attributes on Its Admission Fee Charges
}

\author{
Erda Wang ${ }^{1}$, Jiawei Zhu ${ }^{1}$ and Yang $\mathrm{Yu}^{2}$ \\ ${ }^{1}$ School of Business Management, Dalian University of Technology, No.2 Linggong Road, Dalian, Liaoning, 116024, P. R. China \\ ${ }^{2}$ Yang Yu, Liaoning University of International Business and Economics, P.R. China
}

\begin{abstract}
In this paper, we investigate the effect of those recognized nature-and-activity-based attributes on the level of park's admission fee charges using a panel data of 29 coastal recreation parks in Dalian city of China. A total of seven different Hedonic pricing model specifications are used in the estimating process. The results indicate that a numerous attributes have statistically significant effects $(\alpha \leq 0.10)$ on the level of park admission fee charges. In terms of the economic valuation, the marine sightseeing results in the highest value of Marginal Willingness to Pay (MWTP) of $\$ 6.4$ as its quality rank improves to a designated higher level. As expected that the park congestion has a negative effect on the MWTP (-\$0.47) and overall park's rankings have a positive effect $(\$ 0.05)$ on park's MWTP. However, many recreation activities accommodated by the park sites exhibit a relatively weak effect on the park entrance fee charges. One possible reason is perhaps owing to the single admission package fee policy adopted by the park management..
\end{abstract}

\section{Introduction}

As a result of a rapid tourism development in China, the nature-based park recreation demand has increased dramatically in recent years. Coastal parks endowed with a variety of marine and terrestrial features such as the sea water, mass of sand, and sunlight, so-called $3 \mathrm{~S}$ resources, have become very important tourism attractants attracting millions of tourists to take their vacation and enjoy their leisure times every year not only in China but across over the entire world. Statistical data indicates that over 80 percent of tourism revenue is attributed to the coastal tourism in the United Sates. In the Europe, there are more than 3 million of international coastal arrivals and 2.5 million of domestic coastal arrivals, respectively, per annum (Needham \& Szuster, 2011; Onofri \& Nunes, 2013). By contrast, more than 950 million of the Chinese tourists choose coastal cities as their favorable holiday locations which accounts for $36 \%$ of the total tourism turnout in 2013 (National Bureau of Statistics[NBS], 2014a). However, in comparison with other types of tourism destinations, coastal parks sites bear unique nonsubstitutable ecological features. As such, they are extremely susceptible to human activities (Singh, 2015; Economou \& Mitoula, 2013).

This research tries to fill in that gap by carrying out assessing on the economic importance of those natureand-activity-based coastal attributes in Dalian coastal park areas. In the process, we take the following steps: (i) a comprehensive dataset is synthesized through field surveys of 29 coastal parks, which cover most coastal parks in Dalian city of China. (ii) The established dataset is used to estimate the relationship between park admission fees and their related attributes. Alternative model specifications are established using the control and interaction variables; (iii) the implicit price or tourist's marginal willingness to pay toward each attribute is estimated using the statistical regression model results. The rest of the paper is arranged as follows: Section 2 provides a brief introduction to the study area and data sources. Section 3 gives a detail description for the research methodology and the hedonic model formulations. Section 4 elaborates the model results, and Section 5 discusses procedures used to estimate the visitor's marginal willingness to pay for each specific attribute following by conclusions.

\section{Literature review}

From a recreation product, visitors can derive pleasure and satisfactions from consuming both use and non-use resource values embedded in coastal park resources. According to Lancaster's theory (Lancaster, 1966), all sorts of products can be understood as a bundle of attributes which exhibit some implicit characteristics without any exception. In this sense, actual utility accrued to a recreation trip is primarily determined by the park attributes such as amenity, clean sea water, sea animal species, recreation activity such as sea-animal shows, as well as associated with infrastructure facilities, etc. (Hasegawa, 2010; Alegre \& Sard, 2015). 
The Hedonic Price Method (HPM) is commonly used to value individual attribute embedded in a product and the revealed value information can help firm's product design and marketing strategy as well. Along the same line, the HPM has long been used to estimate the value of environmental goods such as air quality. HPM is frequently utilized in the field of real estate industry to identify the relationship between property price and local environment quality. Since then, the hedonic method has been widely used in valuing goods and services that cannot be priced directly via market transactions (Zygmunt \& Gluszak, 2015). However, most of the studies are focused on price-making for an individual recreation site or activity, for example, price-making for a specific recreational resort and a designed holiday package (Alegre et al., 2013), second home (Saló et al., 2012), a restaurant (Yim et al., 2014) and a hotel room (Schamel, 2012). Certainly, when tourists encounter more inconveniences and/or unpleasant experiences caused by dirty surroundings and crowding conditions, etc., they must result in negative effect on related coastal park admission fee charges, thus causing the park's revenue losses (Taylor, 2008).

\section{Study area and data sources}

\subsection{Study area}

Dalian is located in the east coast of Eurasia and the southern tip of Liaodong Peninsular in the Northeastern China, which faces seas with three directions and one way to the continent. Surrounded by mountains and hills, Dalian has 2,211-kilometers of coastline, of which 139kilometers of the coastal bank is suitable for tourism development. Currently, there are 36 coastal parks and 29 coastal beaches in total in Dalian area. Due to lack of comparative coastal resources in the neighboring areas, the Dalian coastal line becomes a unique asset for its costal tourism development. That is why it's been long viewed as competitive edge for Dalian's regional economic development.

\subsection{Data sources}

The panel data is collected from 29 coastal parks in Dalian city. According to the data documented in the Dalian statistical books, only 5 years of data (2010-2014) are available for analysis. To synthesize the data as best as we can, we search two well-known websites managed by related travel agencies (www.ctrip.com) and (www. qunar.com). The statistical books of the coastal tourism resources are published by the Bureau of China National Statistics, China National Tourism Administration, CNTA, 2008-2014, State Oceanic Administration (2014).

\section{Research method}

\subsection{Framework of empirical model}

The empirical analysis is based on the hedonic pricing model with an underlying assumption that the level of the admission fees charged reflects overall quality of the park's attributes and visitors' preferences. Thus, the park's admission fee can be treated as a function of both nature-based and activity-based characteristics.

$$
P=P\left(x_{m}, z_{n}\right)
$$

To be consistent with the panel data features, the Eq. (1) can be expressed as Eq. (2), where $P_{i t}$ denotes admission fee charged in a coastal park in period $t, x_{m_{u}}$ presents a vector of the nature-based characteristics, and $z_{n_{u t}}$ denotes a vector of activity attributes; subscript $i$ stands for an individual coastal park and $t$ stands for different time periods beginning from the first quarter in 2010 to the fourth quarter in 2014.

$$
P_{i t}=P\left(x_{m_{i t}}, z_{n_{i t}}\right)
$$

Considering the ranking status of each costal park achieved and the number of visitors to attract each year, we add two control variables (ranking and crowding) into the model specifications as shown in Eq. (3). $P($.$) now is$

a linear function of the parameters, $\mathcal{C}_{\text {ranking }}$ and $\mathcal{C}_{\text {crowding }}$ are the two control variables that have potential effects on the level of the park admission fee charges.

$$
\ln P_{i t}=P\left(x_{m_{i t},} z_{n_{i t},} c_{\text {ranking }}, c_{\text {crowding }}\right)+\mu_{i t}
$$

\section{Model results and discussion}

\subsection{Comparison of alternative model specifications}

All the Hausman tests of the models indicate that the random effect is not statistically significant at a conventional statistical significance level (0.05), whereas the fixed effects get to the statistically significant level of 0.05 or lower listed at the bottom of Table 3. Thus, the fixed effect becomes the priority for following analysis work. Additionally, the Durbin-Watson d statistic falls in the range of 1.7-1.9, approximately being equal to ' 2 ' except for model specification \#6 which has the smallest value of $d$ statistic of ' 1.561 ' among all-inclusive model specifications. We believe this is still acceptable. Table 1 shows the estimated results of all the 7 different model specifications based on Eq. (3). Specification \#1 is the base model which uses a semi-log function where both the nature-based and activity-based characteristics are included as explanatory variables. The results indicate that most nature-based attribute variables are significant $(\alpha<0.05)$ except for "sand". Crowding phenomenon has a long been one of the most important problems in all tourism parks in China, especially during the time of the nation's holidays. In order to capture this effect, a control variable of crowding is added to Specification $\# 2$ and it results in a significantly negative coefficient $(\alpha<0.05)$, 
suggesting that congestion indeed has negative effect on traveler's willingness to pay or the park admission fees. In addition, if a park is located in a better coastal environment and at the same time offers better quality services, it will naturally have a better chance to be ranked an ' $A$ ' class than a park which lacks of those features. Therefore, a park ranking variable is added to Eq. (1) in order to examine whether the park ranking status has any markedly effect on the admission fee. It turns out that the ranking variable is not statistically significant (see Specification \#3). Nevertheless, as both variables of crowding and park ranking are added to Eq. (1), the ranking variable becomes statistically significant (see Specification \#4). This suggests that the park ranking status does have a markedly effect on park admission fees. Also, comparison on model results between Specification \#1 and Specification \#4, the adjusted R2 increases from 0.8187 to 0.8977 , implying that the two control variables indeed add extra explanatory power to the park admission fee charges.

Table 1. OLS Estimates of different HPM specifications.

\begin{tabular}{|l|c|c|c|c|}
\hline Specification & $\# \mathbf{1}$ & $\# \mathbf{5}$ & $\# \mathbf{6}$ & $\# 7$ \\
\hline Acre & $\begin{array}{c}0.0184 \\
* * *\end{array}$ & $\begin{array}{c}0.0314 \\
* * *\end{array}$ & & $\begin{array}{c}0.0197 \\
* *\end{array}$ \\
\hline Width & $\begin{array}{c}0.0032 \\
* *\end{array}$ & $\begin{array}{c}0.0032 \\
* * *\end{array}$ & & $\begin{array}{c}0.0028 \\
* *\end{array}$ \\
\hline Sunshine & $\begin{array}{c}0.0190 \\
* *\end{array}$ & $\begin{array}{c}0.0183 \\
* *\end{array}$ & & $\begin{array}{c}0.0098 \\
* * *\end{array}$ \\
\hline Degree & $\begin{array}{c}0.0251) \\
* * *\end{array}$ & $\begin{array}{c}(0.0318) \\
* *\end{array}$ & & $\begin{array}{c}0.0362 \\
* *\end{array}$ \\
\hline Rain & $\begin{array}{c}0.0252) \\
*\end{array}$ & $\begin{array}{c}(0.0253) \\
* *\end{array}$ & & $\begin{array}{c}0.0171) \\
* *\end{array}$ \\
\hline Air & 0.0113 & $0.0154 * *$ & & 0.0208 \\
$* * *$
\end{tabular}

Table 2. Percentage impact and marginal willingness to pay of attribute variations.

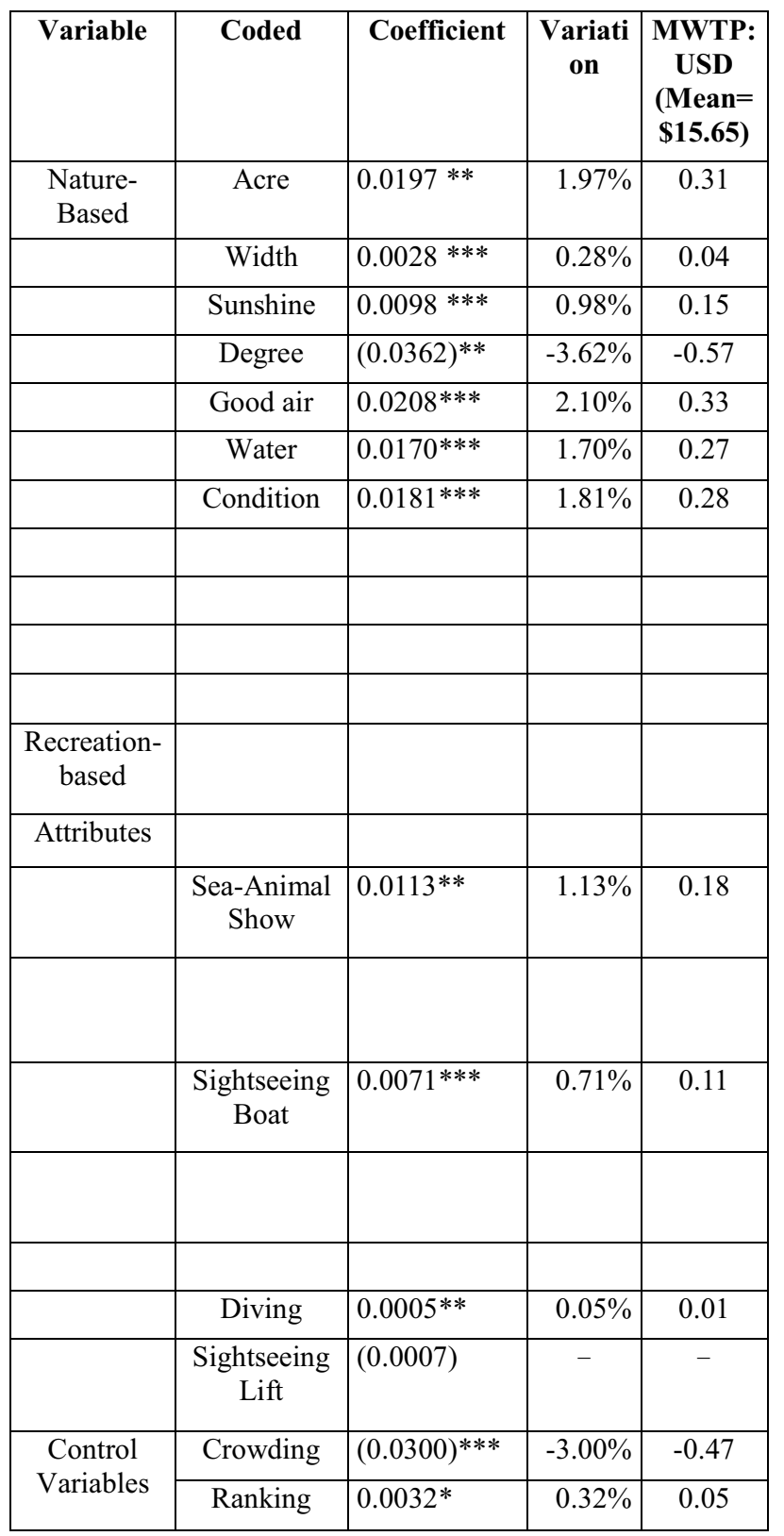

\subsection{Result and discussion}

Overall, the seven model specifications are estimated. The main purpose of making such multitude model estimations is to enhance robustness and comprehensiveness of the analysis. However, only four model results $(\# 1,5,6 \#$, and $\# 7$ ) are presented in Table 1 due to the limited page space. One of the most informative analyses using Hedonic price model is to carry out price elasticity estimate (see Table 2). According to Table 1, most estimated coefficients for the nature-based attributes are positive. Each individual attribute's MWTP is calculated by employing the sample mean of entrance fee of $\$ 15.65$. If the coastal park has a long coastline, its admission fee can be raised by $0.86 \%$ higher than without holding everything else remained constant; marine sightseeing can make the admission fee 
$4.19 \%$ higher as its quality ranking is enhanced by 0.1 point, and similarly, a better sea water quality $(p=0.000)$ can increase the entrance fee by $1.71 \%$ over the base; marine physical condition $(\mathrm{p}=0.000)$ is able to contribute the entrance fee by $1.81 \%$ higher, and seashore sightseeing can raise entrance fee by $0.44 \%$ higher from the base.

Additionally, the mountain existent on the site can raise the entrance fee by more than $0.43 \%$. Furthermore, $1 \%$ enhancement of air quality $(\mathrm{p}=0.000)$ can increase the park admission fee by $2.1 \%$. By contrast, beach sand quality appears to have no statistically significant effect on park admission fee, which may be attributed to the fact that most beaches and coastal banks in the areas present either cobblestones or lower quality sand. The low variable variation contributes to the insignificant coefficient estimation result.

\section{Conclusions}

In this paper, we investigate the effects of both the nature-based and activity-based attributes of a coastal park on its admission fee charges and explore their sequential order to the parks' admission charges using a panel dataset of 29 coastal recreation sites in Dalian city of China. In the process, a total of seven different Hedonic pricing model specifications are estimated in order to demonstrate the robustness and comprehensiveness of the analysis with each model specification involving with different combinations of various explanatory factors.

The estimated results suggest that most sea-related nature attributes such as park size, length of beach, beach width, sunshine, air quality, water quality, etc. exhibit a positive and statistically significant effect on the park admission fee charges except for temperature, number of rainy days, and type of sand. The most important sea related attribute is the marine sightseeing, with the marginal willingness to pay being able to increase by $\$ 6.40$ (\$0.64/0.1 point) as the quality of the marine viewing is improved to one level higher.

Most water related attributes bring about a considerable positive effect on the entrance fees. Furthermore, both congestion and park ranking attributes exert statistically significant effect on park admission fees, suggesting that the park authority should pay more attention to the parks' carrying capacity management. Regarding the activity-based attributes, most of them impose statistically significant $(p<0.1)$ effect on the park's entrance prices. However, those non-water related facilities end up with statistically insignificant results. These may suggest that there is no use for adding those none water-related recreation activities or facilities such as kid playground and fun fair to the coastal parks because they may play a role in detract not adds to the visitors' satisfaction (Loomis \& Richard, 1997; Mueller et al., 2009).

One caveat deserves to mention regarding the overall significance of those assessed attributes in terms of their MWTP for park's admissions. Clearly, the contribution of each nature-based attribute to park entrance fee is underestimated by the model as most attribute changes make a relatively small contribution toward the change of park entrance fee, i.e., less than 3 percent except for temperature (Degree) and condition of marine (Marine). These underestimations are mainly due to the fact that the current entrance fee charging mechanism is under control of the city's government. As such, the coastal parks are treated as public goods, leading to the undervalue use of the resources. Certainly, from an economic efficiency viewpoint, the city government should reassess present coastal park admission charging system. A nature valuebased fee charging system should be encouraged in order to enhance the optimal resource uses, thus to benefit both coastal environment amelioration and visitors' welfare.

This study has limitations in the following two aspects. First, the study did not address coastal tourism market equilibrium issues in Dalian and surround marketing areas. Due to the short of data sources this study did not carry out market equilibrium condition tests prior to constructing the Hedonic pricing models. Nevertheless, the property market equilibrium status test (or coastal tourism market in this study) is generally required in using HP model. Second, as described earlier, at present the coastal park admission fee charging system in Dalian may not fully reflect the true value of the park. Generally speaking, the admission in all parks in Dalian city is undercharged, which could potentially bring about downward biased MWTP estimates for all those attributes analyzed in this study. To improve the quality of this study, the future research may want to expand the study territory by including all the neighboring coastal park areas surrounding Dalian city, so that a larger dataset can be used in estimation, which will ultimately be able to improve the estimate results as more variation for each individual attributes is available in modeling process. In addition, as more marketing mechanism is adopted in determining the level of the entrance fee charges, the MWTP estimate for each considered attribute will be more accurate.

\section{References}

1. J. Alegre, M. Cladera, M. Sard, Tourist areas: Examining the effects of location attributes on touroperator package holiday prices. Tourism Management, 38(0), 131-141, (2013)

2. J. Alegre, M. Sard, When demand drops and prices rise. Tourist packages in the Balearic Islands during the economic crisis, Tourism Management, 46(0), 375-385, (2015)

3. China National Tourism Administration [CNTA], The Yearbook of China Tourism. China Tourism Press: Beijing, China (Total 7 books in Chinese), (2008-2014)

4. Dalian Tourism Administration [DTA] (2010a), The Romantic City of Dalian- official brochure. (2010b) Dalian Bohai Sea Tourism Resources Survey. Liaoning Lijie Consultant Ltd: Liaoning, China. Dalian Tourism Industry Development Programofficial brochure (total 3 books in Chinese), (2014) 
5. A. Economou, R. Mitoula, Management of natural resources and protection of the coastal urban area of Glyfada. Land Use Policy, 35(0), 204-212,(2013)

6. H. Hasegawa, Analyzing tourists' satisfaction: A multivariate ordered probit approach. Tourism Management, 31(1), 86-97, (2010)

7. J. A. Hausman, Specification tests in econometrics. Econometrica: Journal of the Econometric Society, 1251-1271, (1978)

8. K. J. Lancaster, A new approach to consumer theory. The journal of political economy, 132-157, (1966)

9. J. B. Loomis, G. W. Richard, Recreation economic decisions, comparing benefits and costs, second edition, Venture Publishing, Inc., 101-109 (1997)

10. J. Mueller, J. Loomis, A. González-Cabán, Do repeated wildfires change homebuyers' demand for homes in high-risk areas? a hedonic analysis of the short and long-term effects of repeated wildfires on house prices in southern california, Journal of Real Estate Finance \& Economics, 38(2), 155-172, (2009)

11. National Bureau of Statistics of the People's Republic of China, (2010a-2014a), China Statistical Yearbook, (2010b-2014b). China City Statistical Yearbook, (2010c-2014c), Dalian Statistical Yearbook, China Statistics Press: Beijing, China (total 15 books in Chinese)

12. M. D. Needham, B. W. Szuster, Situational influences on normative evaluations of coastal tourism and recreation management strategies in Hawai'i, Tourism Management, 32(4), 732-740, (2011)
13. L. Onofri, P. A. L. D. Nunes, Beach 'lovers' and 'greens': A worldwide empirical analysis of coastal tourism. Ecological Economics, 88(0), 49-56, (2013)

14. A. Saló, A. Garriga, M. Vila, J. M. Sayeras, Differences in seasonal price patterns among second home rentals and hotels: Empirical evidence and practical implications, Tourism Economics, 18(4), 731-747, (2012)

15. G. Schamel, Weekend vs. midweek stays: Modeling hotel room rates in a small market. International Journal of Hospitality Management, 31(4), 1113$1118,(2012)$

16. A. Singh, Managing the environmental problem of seawater intrusion in coastal aquifers through simulation-optimization modeling. Ecological Indicators, 48(0), 498-504, (2015)

17. State Oceanic Administration People's Republic of China, China Marine Statistical Yearbook, China Ocean Press: Beijing, China, (In Chinese), (2014)

18. L. O. Taylor, Theoretical foundations and empirical developments in hedonic modeling. In Hedonic Methods in Housing Markets, (pp. 15-37). Springer New York, (2008)

19. E. S. Yim, S. Lee, W. G. Kim, Determinants of a restaurant average meal price: An application of the hedonic pricing model, International Journal of Hospitality Management, 39(0), 11-20, (2014)

20. R. Zygmunt, M. Gluszak, Forest proximity impact on undeveloped land values: A spatial hedonic study. Forest Policy and Economics, 50(0), 82, (2015) 